\title{
The position of separated children in Ireland who turn 18: Aged out and excluded?
}

\author{
Aoife Horgan
}

School of Applied Social Studies, UCC

\section{Introduction}

My research investigates the position of independent child migrants, referred to as separated children, in Irish society. The research focuses on the transition period from being a separated child to an aged-out minor in Ireland. The transition from childhood to adulthood and turning 18 years of age is a significant one, a day that should be filled with excitement, anticipation and planning how to celebrate the big day with family and friends. For separated children living in Ireland, however, turning 18 can be accompanied by very different emotions and can be the start of a period of great uncertainty.

\section{Who are separated children?}

The Separated Children in Europe Programme (SCEP) is an initiative which was established in 1997 and aims to realise and promote the rights of separated children through the analysis of policy, research and advocacy at both a European and national level. The SCEP describes these children as

'...under 18 years of age, outside their country of origin and separated from both parents, or their previous legal, or customary primary caregiver...' (SCEP, 2009, pp34).

Separated children began arriving in Ireland approximately ten years ago. According to Bhabha, a United States academic who has published widely on this area, separated children migrate from a wide range of countries including Somalia, Sierra Leone, China, Nigeria, Afghanistan, Iraq and Sudan. It is now known that many separated children complete this international migration alone; however a number of separated children are accompanied, some by adults who are unrelated to them while others are brought into destination countries by smugglers or by people trafficking them. There are a multitude of reasons for separated children's migration, including escaping civil upheaval, war and persecution, or they may have been the victims of trafficking or sexual exploitation. In addition to this, according to Mooten, who wrote a report on the circumstances of separated children 
in Ireland for the Irish Refugee Council, separated children may have experienced childspecific forms of persecution such as the forced conscription of child soldiers or female genital mutilation.

\section{Arrival in Ireland}

Ireland, under international commitments such as the United Nations Convention on the Rights of the Child and national law, the Child Care Act 1991, has a duty to care and protect separated children once they arrive in the country. This therefore places a responsibility on the Health Service Executive (HSE) to provide for separated children. However, the initial response towards separated children was very reactive and the development of policy and provision was protracted, with the phenomenon of separated children coming into Ireland being treated as a temporary one. A number of issues were brought to the fore with the arrival of separated children into Ireland, most notably the issue of immigration policy taking priority over care policy. Separated children were viewed as migrants first and children second and, according to Barnardos, this had a negative effect on the quality of care that was provided to separated children. According to the Ombudsman for Children report on separated children living in Ireland, the majority of separated children were accommodated in hostels in Dublin with few or no care staff present. With recent developments in care policy, such as the implementation of the HSE Equity of Care Plan, separated children are now being integrated into Irish society through a system of foster care placements.

\section{Turning 18: Aged-Out Minors}

This process of integration into Irish society is fractured when separated children turn 18 years of age and therefore 'age out' of the care system. Separated children in this position are described as being 'aged-out minors'. While the HSE has an obligation to protect and provide for separated children while they are minors, this responsibility changes once they reach 18 years of age. The majority of separated children have no immigration or legal status, other than being a minor who is in care, and this therefore leads to a position of ambiguity for them. The majority of separated children are transferred from the care of HSE and are placed in the adult system of hostel accommodation for asylum seekers, which is called direct provision. There is a newly implemented policy of targeted dispersal in place for aged-out minors. This policy of targeted dispersal means that once separated children reach 18 years of age, they can be removed from their care placements and dispersed to another part of the country. Previously, aged-out minors would have been accommodated in four dedicated centres in Dublin; however, this new policy means that 
they can be placed in direct provision centres throughout Ireland. Many aged- out minors are forced to leave their communities, friends and schools on turning 18 and cannot complete their leaving certificate. In addition to this, aged-out minors have little access to leaving care services, and there is no statutory obligation to provide aged-out minors with aftercare support. Once placed in direct provision centres, aged-out minors can wait for a decision on their application for asylum for a number of years. They receive a supplement of $€ 19.10$ a week and are not allowed to work or to participate in education.

\section{Case Study}

There is concern being voiced in relation to how the process of separated children ageing out of the care system is being handled and how policy is potentially excluding agedout minors. A recent court case highlighted the lived reality of aged-out minors living in Ireland. Four aged-out minors who had been living in Dublin and were due to complete their Leaving Certificate were moved to Galway under the policy of targeted dispersal in the middle of the school year. In response to this, four aged-out minors took court action against the HSE in an attempt to be allowed to return to the schools they had previously attended to complete their Leaving Certificate there; however, their appeal failed and consequently they had to remain in their areas of dispersal. In relocating aged-out minors under the policy of targeted dispersal, there is the potential that this will isolate them, cut off access to their support network and result in the loss of friendships, in addition to there being no continuity in educational provision for them.

\section{My Research}

My research aims to investigate this transition period from being a separated child in Ireland to becoming an aged-out minor. This transition period presents a number of issues and challenges for aged-out minors living in Ireland and my research seeks to examine the impact and effect that these challenges have on aged-out minors. It will explore the effect of the policy of targeted dispersal in terms of the consequences for aged-out minors and will investigate this in relation to the impact that it has on the loss of friendships, community, participation in education and their social well-being. My research will also explore how the current lack of aftercare support for aged-out minors is impacting on them. This transition period is an area which has been recently highlighted by the Ombudsman for Children as an area of concern, particularly in relation to the lack of any statutory obligation to provide aftercare. In addition, my research will also examine the impact that current policy and legislation in Ireland is having on aged-out minors. 


\section{Method}

My research will use a qualitative method of investigation. This method of research was chosen because of the exploratory nature of this research. Research in recent years has focused on the challenges and circumstances faced by separated children in Ireland, however there has been little research conducted on the experiences of aged-out minors living in Ireland and reports arising are largely descriptive. Utilising a qualitative method of enquiry will enable me to talk to aged-out minors and hear their opinions and thoughts. I will be conducting semi-structured interviews with aged-out minors in order to listen to their lived experiences of this transition period. I will use an interview discussion guide in order to focus the interviews however; participants will also have leeway in how they respond. Central to the discussion in these interviews will be the participants' views on the immediate impact that turning 18 years of age had on their lives, if they were given any information or notice on what would happen when they turned 18 and what life is like now for them. I will also be conducting semi-structured interviews with people working directly with aged-out minors such as social workers, guardian-ad-litems, who are appointed by the Courts to consult with separated children and advise of what is in their best interests, teachers and workers in non-governmental agencies in order to hear their view on this transition period and how it impacts on the lives of aged-out minors.

\section{Ethical Issues}

There are many ethical issues to consider when conducting this type of research. The principle of informed consent will be utilised. Participants will be informed of the purpose of this research and will be assured of confidentiality throughout the research process which will be achieved through the use of pseudonyms. Another issue which needs consideration is disparities of power and ensure the participants do not feel obliged to participate in the research because of a power imbalance between the participant and the researcher. Participation in this research is voluntary and participants can withdraw at any time. I have received ethical approval from the Social Research Ethics Committee within University College Cork.

\section{Conclusion}

The process of separated children ageing out of the care system in Ireland is a new phenomenon and one that requires investigation as the reports that are arising are largely descriptive and do not contain accounts or experiences from aged-out minors. Aged-out minors in Ireland are faced with numerous challenges and the policy of targeted dispersal 
can impact on their lives in relation to the loss of friendships, community, their social wellbeing and result in a lack of continuity in educational provision. While separated children are provided for within the care system, on turning 18 years of age not only do they lose key supports but they also lack a voice in the way policy shapes their future.

Aoife Horgan is a PhD student in the School of Applied Social Studies under the supervision of Dr. Deirdre Horgan and Dr. Shirley Martin. She would like to acknowledge the support of the Irish Research Council for the Humanities and Social Sciences Fund. 